\title{
Central Business Districts and Transit Ridership: A Reexamination of the Relationship in the United States
}

\author{
Jeffrey R. Brown, Florida State University \\ Dristi Neog, Sushant School of Art and Architecture
}

\begin{abstract}
Many scholars claim that public transit's long-term ridership decline can be attributed to the decentralization of U.S. metropolitan areas and the decline of the central business district (CBD) as their primary economic engine. However, recent research has begun to challenge this view and has prompted this reexamination. Using multivariate analysis, we examine the relationship between the strength of the CBD and transit ridership in all U.S. metropolitan areas with more than 500,000 persons in 2000, while controlling for other factors thought to influence bus and rail transit ridership. We find no relationship between the strength of the CBD and transit ridership, which suggests that other factors are much more important contributors to transit ridership.
\end{abstract}

\section{Introduction}

Most scholars argue that public transit's long-term ridership decline is associated with the decentralization of U.S. metropolitan areas and the decline of the central business district (CBD) as their primary economic engine. Recent research suggests that this relationship remains strong, although some scholars have begun to challenge this view by noting circumstances where transit agencies are increasing ridership in decentralized urban areas. These recent research developments have prompted us to reexamine the relationship between the strength of the $\mathrm{CBD}$ and transit ridership 
(measured as transit journey-to-work mode share by bus and/or rail transit modes), while controlling for other factors thought to influence ridership.

\section{The Relationship between Transit Ridership and the CBD}

Transit ridership is one of the most frequently studied phenomena in transportation, and a large literature has emerged that seeks to explain it. The literature divides explanations for ridership (and ridership change) into two broad categories: external factors and internal factors. External factors include urban structure, population change, regional economic conditions, household auto ownership levels, and urban population density, all factors over which transit managers have no control. Internal factors include fare and service policies over which transit managers exercise some control.

\section{Traditional View}

Our particular interest in this study is the role of urban structure in explaining variation in transit ridership, and there is an extensive literature on this topic. Most of the literature focuses on the relationship between transit ridership and the relative strength of the CBD as a locus of regional economic activity. Scholars writing in this topic area tend to view the CBD and the CBD-bound commuter as the most important market for public transit (Pucher and Renne 2003; Pushkarev and Zupan 1977; Pushkarev and Zupan 1980). Mierzejewski and Ball (1990) found support for this view in their survey of transit users, which found that 82 percent of choice riders worked in the CBD of their metropolitan area.

Studies of the post-war decline in U.S. transit use frequently cite the decline of the CBD and the decentralization of population and employment as major causal factors (Ferreri 1992; Jones 1985; Meyer, Kain, and Wohl 1965; Meyer and GómezIbáñez 1981). A number of scholars have used statistical analysis to examine this relationship, when controlling for the influence of other variables. Most of these authors have found strong connections between the strength of the CBD (or its corollary, the degree of decentralization) and transit ridership.

Hendrickson's work (1986) is one example of these studies. He examined the relationship between transit ridership and both the size and strength of the CBD and total population for 25 U.S. metropolitan areas in 1970 and 1980. He found strong, statistically-significant associations between the strength of the CBD and his transit ridership measures. However, his multivariate models failed to control for other important variables, such as fares, service quality, regional economic conditions, and auto ownership, which might also affect transit ridership. He also included 
Central Business Districts and Transit Ridership: A Reexamination of the Relationship in the U.S.

New York, an outlier that accounts for 40 percent of all U.S. transit patronage, in his models, which undoubtedly influenced his results.

Both Gómez-lbáñez (1996) and Kain (1997) performed time-series multivariate analysis to examine the relationship between urban structure and transit ridership in individual metropolitan areas. Gómez-lbáñez (1996) examined ridership change between 1970 and 1990 in Boston. He estimated multivariate models that examined ridership as a function of the number of jobs in Boston (his urban structure variable), per-capita income, fare, service miles, and a dummy variable for 1980-1981, a period during which transit service was significantly reduced. He found that a 1 percent decline in the percent of jobs in the city of Boston was associated with between a 1.24 percent and 1.75 percent decline in ridership, when controlling for the influence of these other variables. However, his definition of employment is problematic and measures jobs located throughout the city of Boston as opposed to jobs inside the CBDs of Boston and Cambridge, which he had originally hoped to measure.

Kain (1997) examined ridership change between 1972 and 1993 in Atlanta. He employed a secular trend variable that functions as an indirect measure of urban decentralization and found that average fares, service levels, total metropolitan employment, and the trend variable were the explanatory variables with the strongest influence on transit ridership. Work by Beesley and Kemp (1987), Heilbrun (1987), Pisarski (1996), and Taylor (1991) provides additional scholarly support for the notion that transit ridership is strongly linked to the strength of the CBD and the degree of urban decentralization.

\section{More Nuanced Views}

However, more recent studies describe a more nuanced relationship between urban structure and transit ridership. In a nine-city case study, Thompson and Matoff (2003) found that transit agencies that altered their service to better serve the dispersed destination patterns that characterized their metropolitan areas increased their ridership. Brown and Thompson (2008a) found similar results in a national study of transit service productivity in 2000. They estimated models predicting service productivity (the ratio of ridership to service) as a function of the strength of the CBD, service orientation, service coverage, fares, fuel prices, auto ownership, regional unemployment rate, West region (a dummy variable), ratio of rail service to total service, and ratio of peak service to off-peak service. They found no relationship between the strength of the CBD and transit productivity when these other factors were included. However, productivity-not ridership-was the focus of their study. 
Ridership is the focus of recent work by Brown and Thompson (2008b) in Atlanta. In a study that updates Kain's earlier analysis, they estimate a time-series model that predicts ridership (measured as passenger miles per capita) as a function of service, fare, motor fuel price, a dummy variable for the 1996 Olympics, and three urban structure variables (percent of MSA [metropolitan statistical area] employment inside the transit service area but outside the $\mathrm{CBD}$, the ratio of employment outside the transit service area to employment inside the transit service area, and the ratio of population outside the transit service area to population inside the transit service area). They find that transit ridership is associated with fares, service, and the two employment variables. Transit ridership is positively associated with the percent of MSA employment inside the transit service area (but outside the $\mathrm{CBD}$ ) and negatively associated with the ratio of employment outside the service area to employment inside the service area. They found that transit ridership is not associated with the strength of the CBD itself, when these other variables are taken into account.

These more nuanced findings prompted our desire to reexamine the link between the strength of the CBD and transit ridership. Our work builds on Hendrickson's (1986) earlier study and addresses some of the limitations of his work. We examine the relationship between transit ridership and the strength of the CBD in 2000, while also controlling for other factors that the literature suggests influence transit ridership. The literature suggests that the key external factors (those outside the control of transit managers) include motor fuel prices (as a surrogate for the overall cost of auto use) (Kain 1997; Pucher 2002), regional unemployment rates (Kain and Liu 1999; Pucher 2002), and the percent of households in the MSA that do not own an automobile (Kain and Liu 1999; Kitamura 1989; Taylor and Miller 2003). The literature suggests that the key internal factors (those within the control of transit managers) include fares (Kain and Liu 1999; McCollom and Pratt 2004; McLeod et al. 1991; Kohn 2000; Stanley and Hyman 2005) and service quality (such as frequency, coverage, and reliability) (Kohn 2000; Pucher 2002; Stanley and Hyman 2005; Taylor and Miller 2003; Thompson and Brown 2006).

\section{Data and Methodology}

The geographic unit for our analysis is the MSA. Other studies have selected individual transit systems (Hartgen and Kinnamon 1999) or urbanized areas (Taylor and Miller 2003) as the unit of analysis, but we rejected these approaches for two reasons. We rejected using individual agencies as our unit of observation because we are interested in the effect of urban structure and, in particular, the strength of the $\mathrm{CBD}$ on overall transit ridership in the metropolitan area without regard to 
Central Business Districts and Transit Ridership: A Reexamination of the Relationship in the U.S.

which transit agency might transport the riders. We rejected using urbanized areas as our unit of analysis because in many metropolitan areas major transit operators provide service across multiple urbanized areas. Attributing service and ridership data to the proper urbanized area in such circumstances is difficult and subject to significant attribution error. We selected the MSA as the geographic unit that would minimize attribution error, and we aggregated all transit variables to this geographic unit. We defined the MSAs to include the areas identified by the Office of Management and Budget (OMB 2005).

We examine the relationship between the strength of the CBD and transit ridership in all U.S. MSAs with more than 500,000 persons, of which there are 82 in the United States as of the 2000 Census. Two are very large MSAs (population in excess of 10 million persons), 8 are large MSAs (population between 5 million and 10 million), 43 are medium MSAs (population between 1 million and 5 million), and 29 are small MSAs (population between 500,000 and 1 million).

We stratify the MSAs into three population size groups. The first group contains all 82 MSAs, the second group contains the 43 medium MSAs, and the third group contains the 29 small MSAs. We stratified our MSAs by population size because there are significant differences in the values of our dependent variable from one MSA size category to the next, as we will discuss shortly. We selected the medium MSA and small MSA groups as specific objects of examination because these groups are large enough to permit the use of multivariate statistical analysis. We included the "all MSA" group as a roundabout method of examining the relationship between the urban structure variable and transit ridership in the very large and large MSAs. By comparing the models for the medium and small MSAs to those for the entire dataset and noting the differences in the behavior of the explanatory variables, we are able to gain some insight into the determinants of transit ridership in these 10 largest MSAs. Our analysis covers the year 2000.

We obtained data from the U.S. Bureau of Economic Analysis, U.S. Bureau of Labor Statistics, U.S. Census Bureau, and National Transit Database. Data from the U.S. Bureau of Economic Analysis included employment and population (by county) for each MSA (U.S. Bureau of Economic Analysis 2006a; U.S. Bureau of Economic Analysis 2006b). Data from the U.S. Bureau of Labor Statistics included MSA unemployment rates (our measure of MSA economic conditions), consumer price index (used to adjust all money variables to 2005 dollars), and motor fuel price index (used as our measure of the cost of using an automobile) (U.S. Bureau of Labor Statistics 2005a; U.S. Bureau of Labor Statistics 2005b; U.S. Bureau of Labor Statis- 
tics 2005c). Data from the U.S. Census Bureau included CBD employment, transit journey to work mode share, and the percent of MSA households that do not own an automobile (U.S. Census Bureau 2000).

We obtained all three variables using the Census Transportation Planning Package (CTPP) software. We defined the CBD for each MSA as encompassing the census tracts identified in the 1982 Census of Retail Trade, but we made minor definitional adjustments after consulting local government and metropolitan planning organization websites in each of the MSAs (U.S. Census Bureau 1982).

We obtained transit data from the National Transit Database using the Florida Department of Transportation's (FDOT) Florida Transit Information System (FTIS) software (FDOT 2005). We extracted agency-specific data and aggregated it into MSA-level data for our analysis. The data we obtained include passenger kilometers, vehicle kilometers, route kilometers, and fare revenue variables. We used the combination of these transit variables and other variables discussed above to construct three ratio variables: (1) service coverage (ratio of route kilometers to population), (2) service frequency (ratio of vehicle kilometers to route kilometers), and (3) fare revenue per passenger kilometer (a proxy for average passenger fare; adjusted to 2005 dollars).

\section{Measure of Urban Centralization versus Decentralization}

Our urban structure variable is the share of MSA employment in the CBD for each MSA (CBD employment divided by total metropolitan employment). Table 1 lists CBD employment, total metropolitan employment, and CBD employment share (by MSA) in 2000. In 2000, Greenville, South Carolina, had the weakest CBD $(0.68$ percent of MSA employment), while New Orleans, Louisiana, had the strongest CBD (10.75 percent of MSA employment). The median MSA had 4.86 percent of its MSA employment inside its CBD in 2000.

We selected employment, as opposed to population, as our measure of centralization versus decentralization for three reasons. First, employment decentralization is the focus of most of the literature on urban decentralization and transit ridership that we discussed earlier in the paper. Second, recent studies have found a closer connection between transit ridership and employment than between ridership and population (Brown and Thompson 2008b). Third, employment tends to be collocated with most other travel destinations, which is why it is used as a proxy for these other destinations in most travel demand models used by transportation planners. We decided to express CBD employment as a percent variable, as opposed to number of jobs in CBD, because CBD size (expressed in count form) 
is correlated with total MSA population and with many other variables that we wished to examine.

\section{Table 1. Distribution of MSA Employment in 2000}

\begin{tabular}{|c|c|c|c|c|c|c|c|}
\hline Metropolitan area & $\begin{array}{r}C B D \\
\text { employment }\end{array}$ & $\begin{array}{l}\text { Metropolitan } \\
\text { employment }\end{array}$ & $\begin{array}{r}C B D \\
\text { employment } \\
\text { share }\end{array}$ & Metropolitan area & $\begin{array}{r}C B D \\
\text { employment }\end{array}$ & $\begin{array}{r}\text { Metropolitan } \\
\text { employment }\end{array}$ & $\begin{array}{r}C B D \\
\text { employment } \\
\text { share }\end{array}$ \\
\hline Albany & 33,860 & 669,984 & $5.05 \%$ & Madison & 30,025 & 390,311 & $7.69 \%$ \\
\hline Albuquerque & 16,760 & 450,430 & $3.72 \%$ & McAllen & 8,205 & 214,392 & $3.83 \%$ \\
\hline Allentown & 6,110 & 391,975 & $1.56 \%$ & Memphis & 24,700 & 769,684 & $3.21 \%$ \\
\hline Atlanta & 115,704 & $2,944,894$ & $3.93 \%$ & Miami & 99,440 & $2,773,734$ & $3.59 \%$ \\
\hline Augusta, GA & 7,465 & 272,743 & $2.74 \%$ & Milwaukee & 53,690 & $1,106,260$ & $4.85 \%$ \\
\hline Austin & 85,930 & 856,866 & $10.03 \%$ & Minneapolis-Saint Paul & 74,285 & $2,324,792$ & $3.20 \%$ \\
\hline Bakersfield & 19,180 & 315,485 & $6.08 \%$ & Mobile & 20,525 & 289,666 & $7.09 \%$ \\
\hline Baton Rouge & 11,385 & 425,367 & $2.68 \%$ & Nashville & 46,915 & 964,117 & $4.87 \%$ \\
\hline Birmingham & 33,190 & 665,183 & $4.99 \%$ & New Orleans & 84,280 & 784,065 & $10.75 \%$ \\
\hline Boston & 170,740 & $3,825,592$ & $4.46 \%$ & New York & 854,165 & $11,977,017$ & $7.13 \%$ \\
\hline Buffalo & 38,425 & 690,064 & $5.57 \%$ & Norfolk & 26,070 & 759,075 & $3.43 \%$ \\
\hline Charleston & 22,925 & 325,669 & $7.04 \%$ & Oklahoma City & 28,755 & 734,979 & $3.91 \%$ \\
\hline Charlotte & 58,530 & $1,208,475$ & $4.84 \%$ & Omaha & 22,050 & 565,875 & $3.90 \%$ \\
\hline Chicago & 349,910 & $5,623,020$ & $6.22 \%$ & Orlando & 29,695 & $1,093,032$ & $2.72 \%$ \\
\hline Cincinnati & 73,925 & $1,280,103$ & $5.77 \%$ & Philadelphia & 229,135 & $3,349,663$ & $6.84 \%$ \\
\hline Cleveland & 109,700 & $1,800,800$ & $6.09 \%$ & Phoenix & 94,595 & $1,469,560$ & $6.44 \%$ \\
\hline Colorado Springs & 17,760 & 348,425 & $5.10 \%$ & Pittsburgh & 95,550 & $1,437,430$ & $6.65 \%$ \\
\hline Columbia & 36,435 & 441,058 & $8.26 \%$ & Portland & 96,490 & $1,240,232$ & $7.78 \%$ \\
\hline Columbus & 88,755 & $1,232,309$ & $7.20 \%$ & Providence & 24,295 & 507,785 & $4.78 \%$ \\
\hline Dallas & 97,115 & $3,543,629$ & $2.74 \%$ & Raleigh & 29,805 & 896,853 & $3.32 \%$ \\
\hline Dayton & 26,240 & 640,566 & $4.10 \%$ & Richmond & 55,850 & 712,533 & $7.84 \%$ \\
\hline Denver & 131,320 & $1,778,661$ & $7.38 \%$ & Rochester & 33,885 & 673,936 & $5.03 \%$ \\
\hline Detroit & 78,630 & $3,106,495$ & $2.53 \%$ & Sacramento & 64,805 & $1,141,068$ & $5.68 \%$ \\
\hline E1 Paso & 13,180 & 326,272 & $4.04 \%$ & Saint Louis & 80,326 & $1,689,548$ & $4.75 \%$ \\
\hline Fort Wayne & 17,965 & 365,551 & $4.91 \%$ & Salt Lake City & 50,770 & 972,095 & $5.22 \%$ \\
\hline Fresno & 32,290 & 465,271 & $6.94 \%$ & San Antonio & 55,090 & 988,993 & $5.57 \%$ \\
\hline Grand Rapids & 24,005 & 767,146 & $3.13 \%$ & San Diego & 61,830 & $1,733,524$ & $3.57 \%$ \\
\hline Greensboro & 16,205 & 907,566 & $1.79 \%$ & San Francisco & 184,450 & $4,799,756$ & $3.84 \%$ \\
\hline Greenville & 4,560 & 670,717 & $0.68 \%$ & Sarasota & 19,715 & 355,250 & $5.55 \%$ \\
\hline Harrisburg & 26,260 & 436,122 & $6.02 \%$ & Scranton & 13,425 & 311,207 & $4.31 \%$ \\
\hline Hartford & 38,900 & 811,186 & $4.80 \%$ & Seattle & 97,055 & $2,340,450$ & $4.15 \%$ \\
\hline Honolulu & 31,340 & 562,384 & $5.57 \%$ & Springfield & 13,540 & 370,158 & $3.66 \%$ \\
\hline Houston & 153,420 & $2,891,102$ & $5.31 \%$ & Stockton & 12,980 & 259,492 & $5.00 \%$ \\
\hline Indianapolis & 87,090 & $1,215,606$ & $7.16 \%$ & Syracuse & 25,405 & 414,395 & $6.13 \%$ \\
\hline Jacksonville & 60,605 & 718,051 & $8.44 \%$ & Tampa & 56,530 & $1,454,420$ & $3.89 \%$ \\
\hline Kansas City & 30,450 & $1,262,663$ & $2.41 \%$ & Toledo & 18,070 & 445,992 & $4.05 \%$ \\
\hline Knoxville & 17,205 & 476,879 & $3.61 \%$ & Tucson & 9,700 & 444,366 & $2.18 \%$ \\
\hline Las Vegas & 30,840 & 877,399 & $3.51 \%$ & Tulsa & 33,590 & 563,556 & $5.96 \%$ \\
\hline Little Rock & 32,915 & 481,277 & $6.84 \%$ & Washington, DC & 179,660 & $5,081,129$ & $3.54 \%$ \\
\hline Los Angeles & 170,000 & $9,152,692$ & $1.86 \%$ & Wichita & 26,685 & 389,045 & $6.86 \%$ \\
\hline Louisville & 78,070 & 823,299 & $9.48 \%$ & Youngstown & 8,040 & 368,948 & $2.18 \%$ \\
\hline
\end{tabular}

Sources: US Census Bureau (2000), US Bureau of Economic Analysis (2006a).

\section{Measure of transit ridership}

We measured transit ridership as transit journey-to-work (commute) mode share. This variable measures the percent of work trips made by public transit, and hence is focused solely on commute travel. We hypothesized that this variable would be more strongly influenced by the strength of the CBD than a more general ridership measure, such as passenger kilometers per capita, because the CBD is primarily a destination for work trips. 
Table 2 reports the 2000 values for transit journey-to-work (commute) mode share by MSA. The smallest reported value for 2000 is found for McAllen, Texas ( 0.32 percent), while New York has the highest reported value (24.7 percent). The median MSA had a transit commute mode share of 1.98 percent in 2000.

We found significant differences in transit commute mode share among MSAs in our four population size groups. The median value for MSAs in the very large MSA group (population over 10 million, $14.7 \%$ mode share) is 60 percent higher than the corresponding value for the large MSA group (population from 5 million to 10 million, $8.8 \%$ mode share). The median values for our smaller population groups are much lower than these values. The median value for our medium MSAs (population 1 million to 5 million, $2.4 \%$ mode share) is nearly twice as large as that for the small MSA group (population from 500,000 to 1 million, 1.2\% mode share). These differences reinforced our decision to stratify the MSAs by group size for our multivariate analysis.

\section{Hypotheses}

The literature suggests that transit ridership is tied to a metropolitan area's urban structure and, in particular, to the strength of the CBD as a locus of economic activity. The purpose of this paper is to test this hypothesis, while also controlling for other internal and external factors that are hypothesized to influence transit ridership. We include the following variables in each of our models:

1. Percent of MSA employment in the CBD. This variable is our $C B D$ strength variable and can be used to measure the degree of employment centralization or decentralization in the MSA. Based on the literature, we would expect to find a positive relationship between the percent of MSA employment in the $\mathrm{CBD}$ and transit ridership.

2. Fare per passenger kilometer (adjusted to 2005 dollars). This is a variable that is at least partially under the control of transit agency managers. We expect that MSAs where transit agencies have higher fares will have lower ridership.

3. Service frequency (ratio of vehicle kilometers to route kilometers). This is a variable that is at least partially under the control of transit agency managers. We expect that MSAs where transit agencies offer more frequent service will have higher ridership.

4. Service coverage (ratio of route kilometers to population). This is a variable that is at least partially under the control of transit agency managers. We 
Table 2. Transit Journey-to-Work (Commute) Mode Share (by MSA) in 2000

\begin{tabular}{|c|c|c|c|}
\hline Metropolitan area & $\begin{array}{c}2000 \text { transit commute } \\
\text { mode share }\end{array}$ & Metropolitan area & $\begin{array}{c}2000 \text { transit commute } \\
\text { mode share }\end{array}$ \\
\hline Albany & $3.28 \%$ & Madison & $3.61 \%$ \\
\hline Albuquerque & $1.23 \%$ & McAllen & $0.32 \%$ \\
\hline Allentown & $1.29 \%$ & Memphis & $1.70 \%$ \\
\hline Atlanta & $3.70 \%$ & Miami & $3.80 \%$ \\
\hline Augusta, GA & $0.69 \%$ & Milwaukee & $4.00 \%$ \\
\hline Austin & $2.60 \%$ & Minneapolis-Saint Paul & $4.50 \%$ \\
\hline Bakersfield & $1.37 \%$ & Mobile & $0.76 \%$ \\
\hline Baton Rouge & $2.10 \%$ & Nashville & $1.00 \%$ \\
\hline Birmingham & $0.75 \%$ & New Orleans & $5.50 \%$ \\
\hline Boston & $8.90 \%$ & New York & $24.70 \%$ \\
\hline Buffalo & $3.60 \%$ & Norfolk & $1.80 \%$ \\
\hline Charleston & $1.61 \%$ & Oklahoma City & $0.60 \%$ \\
\hline Charlotte & $1.40 \%$ & Omaha & $1.08 \%$ \\
\hline Chicago & $11.50 \%$ & Orlando & $1.70 \%$ \\
\hline Cincinnati & $2.90 \%$ & Philadelphia & $8.70 \%$ \\
\hline Cleveland & $3.50 \%$ & Phoenix & $2.00 \%$ \\
\hline Colorado Springs & $0.93 \%$ & Pittsburgh & $6.20 \%$ \\
\hline Columbia & $1.17 \%$ & Portland & $5.60 \%$ \\
\hline Columbus & $2.30 \%$ & Providence & $2.50 \%$ \\
\hline Dallas & $1.80 \%$ & Raleigh & $1.70 \%$ \\
\hline Dayton & $1.85 \%$ & Richmond & $1.96 \%$ \\
\hline Denver & $4.40 \%$ & Rochester & $2.00 \%$ \\
\hline Detroit & $1.80 \%$ & Sacramento & $2.80 \%$ \\
\hline El Paso & $2.22 \%$ & Saint Louis & $2.40 \%$ \\
\hline Fort Wayne & $0.72 \%$ & Salt Lake City & $3.00 \%$ \\
\hline Fresno & $1.73 \%$ & San Antonio & $2.90 \%$ \\
\hline Grand Rapids & $0.80 \%$ & San Diego & $3.40 \%$ \\
\hline Greensboro & $0.80 \%$ & San Francisco & $9.30 \%$ \\
\hline Greenville & $0.38 \%$ & Sarasota & $0.66 \%$ \\
\hline Harrisburg & $1.43 \%$ & Scranton & $0.94 \%$ \\
\hline Hartford & $2.80 \%$ & Seattle & $6.30 \%$ \\
\hline Honolulu & $8.31 \%$ & Springfield & $2.34 \%$ \\
\hline Houston & $3.20 \%$ & Stockton & $1.43 \%$ \\
\hline Indianapolis & $1.30 \%$ & Syracuse & $2.08 \%$ \\
\hline Jacksonville & $1.50 \%$ & Tampa & $1.30 \%$ \\
\hline Kansas City & $1.30 \%$ & Toledo & $1.36 \%$ \\
\hline Knoxville & $0.53 \%$ & Tucson & $2.53 \%$ \\
\hline Las Vegas & $4.00 \%$ & Tulsa & $0.65 \%$ \\
\hline Little Rock & $0.84 \%$ & Washington, DC & $9.40 \%$ \\
\hline Los Angeles & $4.70 \%$ & Wichita & $0.58 \%$ \\
\hline Louisville & $2.20 \%$ & Youngstown & $0.53 \%$ \\
\hline
\end{tabular}

Source: US Census Bureau (2000) 
expect that MSAs where transit agencies offer more service coverage will have higher ridership.

5. Percent of MSA households that do not own an automobile. This is an external variable (i.e., not under the control of agency managers) that may influence transit ridership. Based on the literature discussed earlier, we expect that MSAs that have higher percentage of carless households will have higher levels of transit ridership.

6. MSA unemployment rate. This is an external variable that may influence transit ridership. We expect that MSAs with higher unemployment rates will have lower ridership, because riders would have less need to use transit to reach jobs.

7. Fuel price index. This is an external variable that may influence transit ridership. We use this variable as a general proxy for the cost of using an automobile. We expect that MSAs with high fuel prices will have high transit ridership.

\section{Model Specification}

We estimated three cross-sectional multivariate ordinary least squares regression models to test our hypotheses. We estimate separate models for all MSAs, medium MSAs, and small MSAs. Through comparison with the medium MSA and small MSA models, we can treat the all MSA model as a pseudo-model for the very large and large MSAs.

In evaluating the explanatory variables in each of the models, we are interested in the presence (or lack thereof) of statistical relationships and the practical importance of the statistical association. To measure practical importance, we use elasticity. In order to obtain elasticities, we transformed all the variables into their natural log forms. After this transformation, the coefficients for each explanatory variable can be read as the elasticity of the transit ridership variable with respect to the explanatory variable. We report descriptive statistics for our transformed variables in Table 3.

We tested the use of MSA population as a control variable, but decided not to include it because it was not statistically significant in any of our preliminary models. Our MSA stratification appears to have accounted for the variation in transit ridership (by population size group) discussed earlier in the paper. We also tested the percent of MSA population made up of recent immigrants in our preliminary tests but decided not to include it because it was not correlated with our transit ridership variables. We suspect this is due to the wide dispersion of immigrant populations throughout the United States. We considered the inclusion of a vari- 
Central Business Districts and Transit Ridership: A Reexamination of the Relationship in the U.S.

able measuring density, but decided not to include such a variable because only metropolitan-scale measures of density (urbanized area density, MSA density) were available for all 82 MSAs.

\section{Table 3. Descriptive Statistics for All Variables}

\begin{tabular}{|c|c|c|c|c|}
\hline & Mean & Median & $\begin{array}{l}\text { Standard } \\
\text { deviation }\end{array}$ & $\begin{array}{r}\text { Standard } \\
\text { error } \\
\end{array}$ \\
\hline (Natural Log of) Transit commute mode share & 0.708 & 0.683 & 0.842 & 0.093 \\
\hline $\begin{array}{l}\text { (Natural Log of) Percent of MSA employment in } \\
\text { the CBD }\end{array}$ & 1.518 & 1.581 & 0.459 & 0.459 \\
\hline $\begin{array}{l}\text { (Natural Log of) Fare per passenger kilometer } \\
\text { (2005 dollars) }\end{array}$ & -1.737 & -1.757 & 0.433 & 0.433 \\
\hline $\begin{array}{l}\text { (Natural Log of) Service frequency (ratio of } \\
\text { vehicle kilometers to route kilometers) }\end{array}$ & 9.101 & 9.172 & 0.605 & 0.605 \\
\hline $\begin{array}{l}\text { (Natural Log of) Service coverage (ratio of route } \\
\text { kilometers to population) }\end{array}$ & -7.234 & -7.122 & 0.557 & 0.557 \\
\hline $\begin{array}{l}\text { (Natural Log of) Percent of MSA households that } \\
\text { do not own an auto }\end{array}$ & 2.165 & 2.134 & 0.289 & 0.289 \\
\hline (Natural Log of) Unemployment rate & 1.271 & 1.224 & 0.379 & 0.379 \\
\hline (Natural Log of) Fuel Price Index & 4.860 & 4.845 & 0.018 & 0.345 \\
\hline
\end{tabular}

\section{Multivariate Analysis of Transit Ridership}

As noted above, we transformed all variables into their natural log forms in order to observe simultaneously 1 ) the statistical significance of the relationship between each explanatory variable and our dependent variable (when controlling for all other explanatory variables) and 2) the elasticity of the dependent variable with respect to the explanatory variable. The unstandardized coefficients in the tables can be read directly as elasticities. Statistical tests revealed no multicollinearity issues among the variables in our models. Test results are shown under the collinearity statistics columns of each model table.

The model results for all 82 MSAs are shown in Table 4. This "all MSAs" model has very high $\mathrm{R}$ squared and $\mathrm{F}$ statistics, indicating that the model has strong explanatory power. The key insight from the model is the absence of a statistical relationship between the strength of the CBD and transit commute mode share, when other explanatory variables are taken into consideration. This finding thus differs from the traditional view in the literature that posits a strong link between transit ridership and the strength of the CBD.

There are four explanatory variables that have statistically-significant relationships with transit commute mode share (at the 0.05 significance level). These variables 
are service frequency, service coverage, percent of MSA households that do not own cars, and unemployment rate. All four variables behaved as hypothesized. Two variables (service frequency and coverage) are under the control of transit managers. As service frequency and coverage increase, so does the transit commute mode share. The elasticities indicate that service frequency has a stronger effect on commute mode share than service coverage (elasticities of 0.906 and 0.635 , respectively). This finding is consistent with other literature.

The other two variables are beyond the control of transit managers. Perhaps not surprisingly, the larger the share of carless households in the MSA, the higher the transit commute mode share. In fact, this variable has the strongest effect on transit commute mode share (elasticity of 0.949 ). In addition, and also not surprisingly, the economic health of the metropolitan area has an effect on the transit commute mode share. As unemployment rates increase, transit commute mode share falls.

The second model, shown in Table 5, focuses on the relationship between transit commute mode share and our set of explanatory variables in the medium sized MSAs (population of 1 million to 5 million). The model has high $R$ squared and $F$ statistics, indicating that it is a strong explanatory model. As with our first model, we found no statistical relationship between the strength of the CBD and transit ridership.

Three of the four explanatory variables that were significant in the first model are also significant in this model. These variables are: service frequency, service coverage, and the percent carless households. All three variables behaved as hypothesized. As in the first model, MSAs whose transit agencies offered more frequent service and/or better service coverage had higher transit commute mode shares. As in the first model, MSAs with a higher percent of carless households had higher transit commute mode shares. These variables are inelastic with respect to transit commute mode share, with a similar rank order pattern as the model for all MSAs.

The third model, shown in Table 6, focuses on the relationship between transit commute mode share and our set of explanatory variables in the small MSAs (population 500,000 to $1,000,000$ ). Again, the $R$ squared and $F$ statistics indicate that this is a powerful model. This is the only one of the three models where our multicollinearity test statistics are not comfortably within widely acceptable ranges. One variable, percent of MSA households that do not own a car, has collinearity statistics that are just barely beyond this range, although the statistics are negligible. 


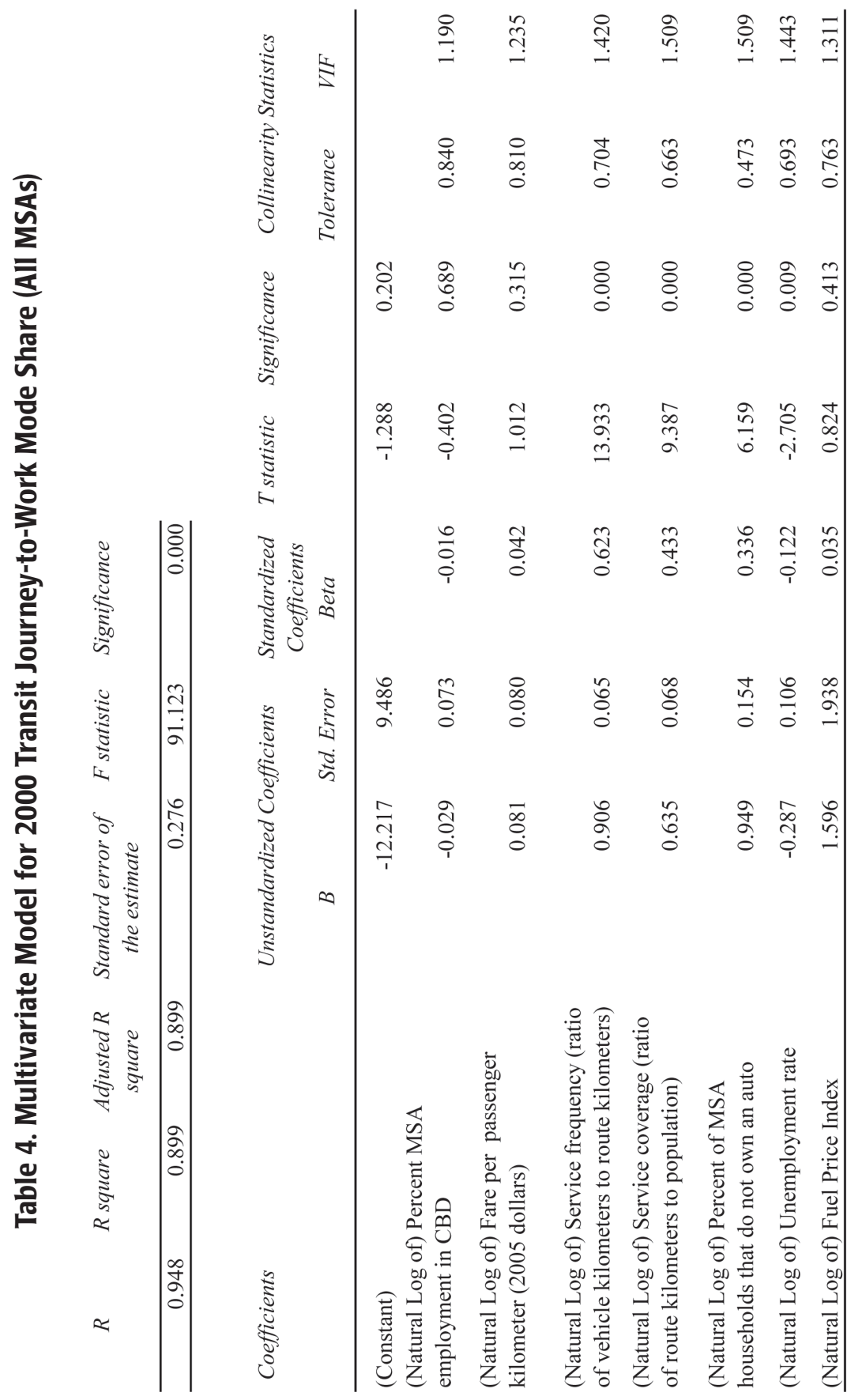




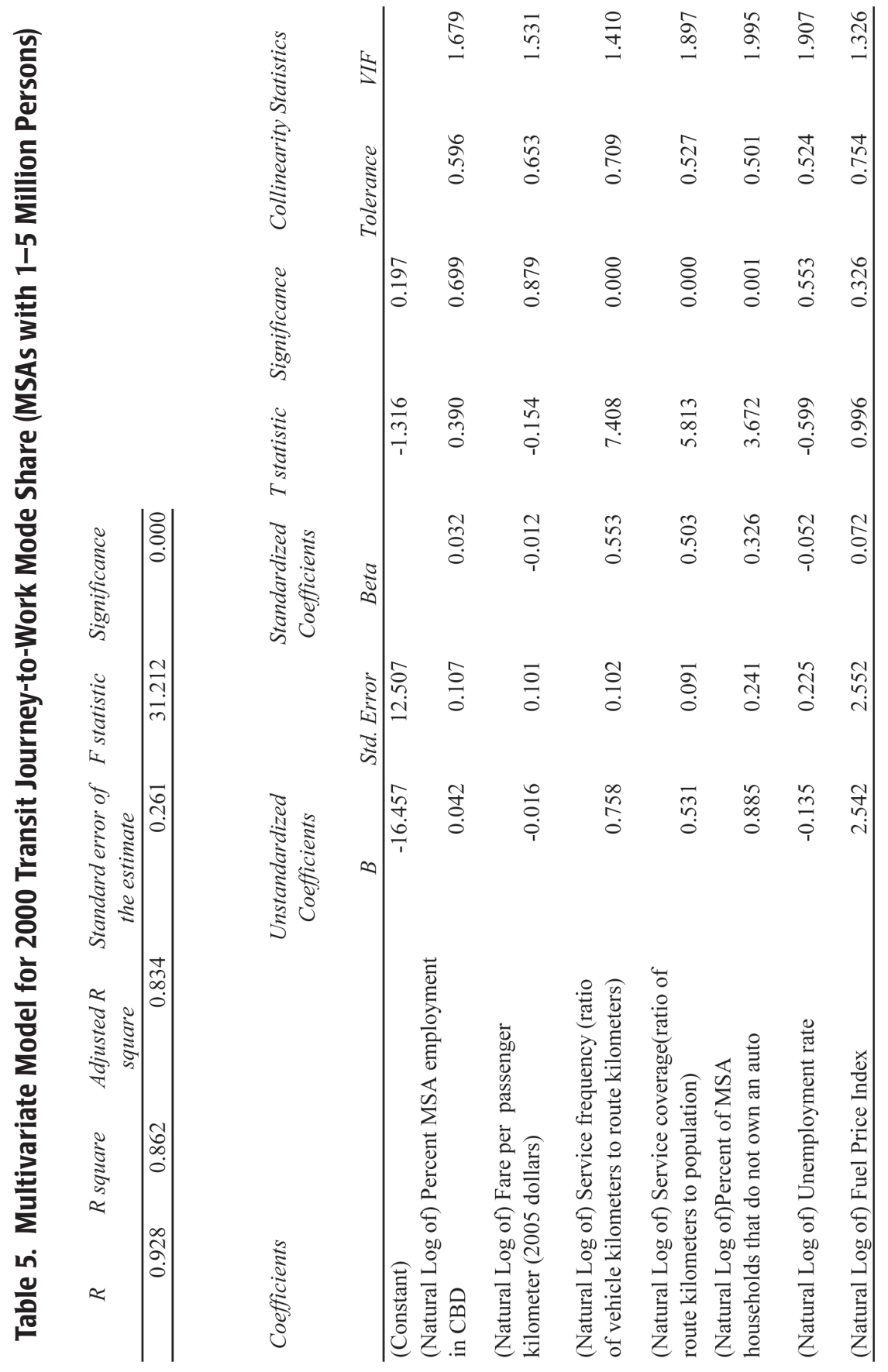


Central Business Districts and Transit Ridership: A Reexamination of the Relationship in the U.S.

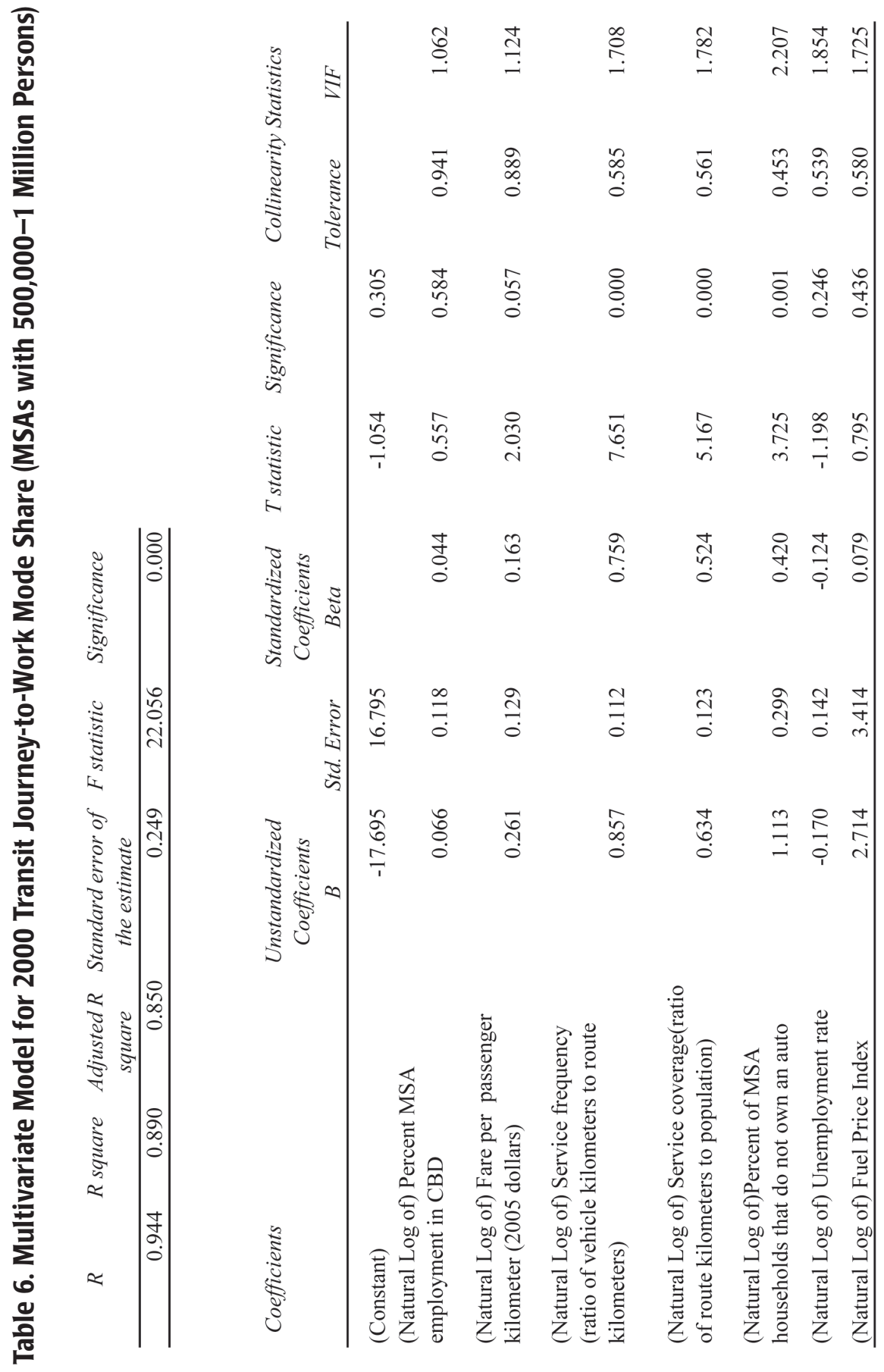


The results of the small MSA model are very similar to the results for the other two models. As before, we found no statistically significant association between strength of the $\mathrm{CBD}$ and transit commute mode share, when other explanatory variables are taken into account. As with the other models, the service frequency, service coverage and percent carless household variables are significant and behave as expected. As with the other models, service frequency is more important than ridership (elasticities of 0.857 and 0.634 , respectively), although the percent carless household variable is the most important of the three explanatory variables (elasticity of 1.113).

In summary, the three models show that $\mathrm{CBD}$ strength is not associated with transit commute mode share. This finding runs counter to our initial hypotheses (see Table 7). However, all the statistically significant relationships are consistent with our initial hypotheses.

\section{Discussion}

Our multivariate analysis indicates that transit commute mode share is not tied to the strength of the $\mathrm{CBD}$ when we take into account the other important influences on transit ridership discussed by the literature. The lack of any meaningful statistical connection between the strength of the $\mathrm{CBD}$ and transit commute mode share is at odds with some of the literature cited earlier, but this disconnect can be explained. First, the literature cited earlier that reflects the traditional view either defines the strength of the CBD differently (as, for example, the absolute number of jobs in the $\mathrm{CBD}$ ) or relies on very simple models that do not control for other variables that the authors themselves recognize can influence transit ridership. Second, our results are consistent with an emerging body of literature, best exemplified by Brown and Thompson (2008b), which examines the link between transit patronage and the distribution of employment in more nuanced ways. They distinguished between 1) employment inside the CBD, 2) employment outside the CBD but inside the transit service area, and 3) employment outside the transit service area. They found a strong link between the latter two types of employment and transit ridership (positive with respect to the second type of employment and negative with respect to the third type of employment). We were unable to obtain a variable equivalent to their measure of MSA employment outside the CBD but inside the transit service area. It is likely that if we had been able to do so, our results would have echoed their findings. 


\section{Table 7. Evaluation of Expected Relationships}

\begin{tabular}{|c|c|c|c|}
\hline \multirow[b]{2}{*}{ Explanatory variable } & \multirow[b]{2}{*}{ Expected behavior } & \multicolumn{2}{|c|}{ Demonstrated behavior } \\
\hline & & Sign & Significance $(\mathbf{Y} / \mathbf{N})$ \\
\hline (Natural Log of) Percent MSA employment in CBD & Positive & Negative & No \\
\hline $\begin{array}{l}\text { (Natural Log of) Fare per passenger kilometer ( } 2005 \\
\text { dollars) }\end{array}$ & Negative & Positive & No \\
\hline $\begin{array}{l}\text { (Natural Log of) Service frequency (ratio of vehicle } \\
\text { kilometers to route kilometers) }\end{array}$ & Positive & Positive & Yes \\
\hline $\begin{array}{l}\text { (Natural Log of) Service coverage(ratio of route } \\
\text { kilometers to population) } \\
\text { (Natural Log of)Percent of MSA households that do }\end{array}$ & Positive & Positive & Yes \\
\hline not own an auto & Positive & Positive & Yes \\
\hline (Natural Log of) Unemployment rate & Negative & Negative & Yes \\
\hline (Natural Log of) Fuel Price Index & Positive & Positive & No \\
\hline
\end{tabular}

MSAs with 1 million to 5 million persons

\begin{tabular}{lccc} 
& & \multicolumn{2}{c}{ Demonstrated behavior } \\
\cline { 3 - 4 } Explanatory variable & Expected behavior & Sign & Significance (Y/N) \\
\hline $\begin{array}{l}\text { (Natural Log of) Percent MSA employment in CBD } \\
\text { (Natural Log of) Fare per passenger kilometer (2005 } \\
\text { dollars) }\end{array}$ & Positive & Positive & No \\
$\begin{array}{l}\text { (Natural Log of) Service frequency (ratio of vehicle } \\
\text { kilometers to route kilometers) }\end{array}$ & Negative & Negative & No \\
$\begin{array}{l}\text { (Natural Log of) Service coverage(ratio of route } \\
\text { kilometers to population) }\end{array}$ & Positive & Positive & Yes \\
$\begin{array}{l}\text { (Natural Log of)Percent of MSA households that do } \\
\text { not own an auto }\end{array}$ & Positive & Positive & Yes \\
$\begin{array}{l}\text { (Natural Log of) Unemployment rate } \\
\text { (Natural Log of) Fuel Price Index }\end{array}$ & $\begin{array}{c}\text { Positive } \\
\text { Negative }\end{array}$ & $\begin{array}{c}\text { Positive } \\
\text { Negative } \\
\text { Positive }\end{array}$ & Yes \\
\hline
\end{tabular}

\section{MSAs with 500,000 to 1 million persons}

\section{Explanatory variable}

Expected behavior $\mathrm{Si}$

Demonstrated behavior

(Natural Log of) Percent MSA employment in CBD

(Natural Log of) Fare per passenger kilometer (2005 dollars)

(Natural Log of) Service frequency (ratio of vehicle

kilometers to route kilometers)

(Natural Log of) Service coverage(ratio of route

kilometers to population)

(Natural Log of)Percent of MSA households that do not own an auto

(Natural Log of) Unemployment rate

Sign Significance $(\mathrm{Y} / \mathrm{N})$

(Natural Log of) Fuel Price Index

$\begin{array}{lll}\text { Positive } & \text { Positive } & \text { No } \\ \text { Negative } & \text { Positive } & \text { No } \\ \text { Positive } & \text { Positive } & \text { Yes } \\ \text { Positive } & \text { Positive } & \text { Yes } \\ \text { Positive } & \text { Positive } & \text { Yes } \\ \text { Negative } & \text { Negative } & \text { No } \\ \text { Positive } & \text { Positive } & \text { No }\end{array}$


Transit commute mode share is, however, tied to several other variables, some of which are (at least partially) within the control of transit managers. Higher transit ridership is strongly associated with higher service frequency and is also associated, albeit slightly less strongly, with better service coverage. Our analysis suggests that agencies will be rewarded with higher ridership if they improve their service frequency or their coverage. However, the likely effects of these policy decisions on service productivity cannot be inferred from this analysis. Of course, it is possible that the key service variables (route miles and service frequency) have larger values where ridership is higher, which raises the possibility that they are endogenous variables. However, the consistency of these statistical results with other work, particularly in the service orientation and service productivity literature, suggests that this might not be the case and that riders are indeed responding to agency decisions to provide better service in more locations (Brown and Thompson 2008c). Transit ridership is also tied to factors beyond the control of transit agency managers, including the percent of carless households in the MSA. Unemployment rates are also important, as indicators of overall regional economic health, in particular MSA settings.

Based on our finding that transit commute mode share is not tied to CBD strength, there is the suggestion that transit managers have adjusted their service strategies to better serve decentralized urban environments. However, further research is required to identify the specific strategies they have employed and to determine the effectiveness of these strategies.

\section{References}

Beesley, M., and M. Kemp. 1987. Urban transportation. In Mills, E. (ed.), Handbook of Regional and Urban Economics, Volume II: Urban Economics. North Holland Press, Amsterdam.

Brown, J., and G. Thompson. 2008a. Examining the influence of multi-destination service orientation on transit service productivity: A multivariate analysis. Transportation 35(2): 237-252.

Brown, J., and G. Thompson. 2008b. The relationship between transit ridership and urban decentralization: Insights from Atlanta. Urban Studies 45(5\&6): 1119-1139. 
Central Business Districts and Transit Ridership: A Reexamination of the Relationship in the U.S.

Brown, J., and G. Thompson. 2008c. Service orientation, bus-rail service integration, and transit performance: An examination of 45 U.S. metropolitan areas. Transportation Research Record 2042: 82-89.

Ferreri, M. 1992. Comparative costs. In Gray, G. E., and L. A. Hoel (eds.), Public Transportation, Second Edition. Prentice-Hall, Englewood Cliffs, NJ.

Florida Department of Transportation. 2005. Florida Transit Information System 2005. Available for download at Ictr.eng.fiu.edu/ftis/.

Gómez-lbáñez, J. 1996. Big city transit ridership, deficits and politics: Avoiding reality in Boston. Journal of the American Planning Association 62(1): 30-50.

Hartgen, D., and M. Kinnamon. 1999. Comparative Performance of Major U.S. Bus Transit Systems, 1988-1997. Sixth Edition. Charlotte, NC: Center for Interdisciplinary Transportation Studies, University of North Carolina at Charlotte.

Heilbrun, J. 1987. Urban Economics and Public Policy, Third Edition. St. Martin's Press, New York.

Hendrickson, C. 1986. A note on trends in transit commuting in the United States relating to employment in the central business district. Transportation Research Part A 20(1): 33-37.

Jones, D. 1985. Urban Transit Policy: An Economic and Political History. PrenticeHall, Englewood Cliffs, New Jersey.

Kain, J. 1997. Cost-effective alternatives to Atlanta's rail rapid transit system. Journal of Transport Economics and Policy January: 25-49.

Kain, J., and Z. Liu. 1999. Secrets of success: Assessing the large increases in transit ridership achieved by Houston and San Diego transit providers. Transportation Research Part A 33(7/8): 601-624.

Kitamura, R. 1989). A causal analysis of car ownership and transit use. Transportation 16(2): 155-173.

Kohn, H. 2000. Factors affecting urban transit ridership. Paper presented at the Bridging the Gaps Conference, Charlottetown, PEl, Canadian Transportation Research Forum.

McCollom, B., and R. Pratt. 2004. Transit pricing and fares. In Traveler Response to Transportation System Changes, Report 95, Transit Cooperative Research 
Program, Transportation Research Board, National Research Council, Washington, D.C.

McLeod, M., K. Flannelly, L. Flannelly, and R. Behnke. 1991. Multivariate time-series model of transit ridership based on historical, aggregate data: The past, present and future of Honolulu. Transportation Research Record 1297: 76-84.

Meyer, J., and J. Gómez-Ibáñez. 1981. Autos, Transit, and Cities. Harvard University Press, Cambridge, MA.

Meyer, J., J. Kain, and M. Wohl. 1965. The Urban Transportation Problem. Harvard University Press, Cambridge, MA.

Mierzejewski, E., and W. Ball. 1990. New findings on factors related to transit use. ITE Journal, February: 34-39.

Office of Management and Budget, Executive Office of the President. 2005. Update of statistical area definitions and guidance on their uses. OMB Bulletin 06-01, dated December 5.

Pisarski, A. 1996. Commuting in America II. Eno Foundation, Washington, D.C.

Pucher, J. 2002. Renaissance for public transport in the United States. Transportation Quarterly 56 (1): 33-49.

Pucher, J., and J. Renne. 2003. Socioeconomics of urban travel: Evidence from the 2001 NHTS. Transportation Quarterly 57 (3): 49-78.

Pushkarev, B., and J. Zupan. 1977. Public Transportation and Land Use Policy. Indiana University Press, Bloomington, IN.

Pushkarev, B., and J. Zupan. 1980. Urban Rail in America. Indiana University Press, Bloomington, IN.

Stanley, R., and R. Hyman. 2005. Evaluation of recent ridership increases. Research Results Digest 69, Transit Cooperative Research Program, Transportation Research Board, National Research Council, Washington, D.C.

Taylor, B. 1991. Unjust equity: An examination of California's transportation development act. Transportation Research Record 1297: 85-92.

Taylor, B., and D. Miller. 2003. Analyzing the determinants of transit ridership using a two-stage least squares regression on a national sample of urbanized areas. Paper presented at the 82nd Annual Meeting of the Transportation Research Board, Washington, D.C. 
Central Business Districts and Transit Ridership: A Reexamination of the Relationship in the U.S.

Thompson, G. and Brown, J. 2006. Explaining variation in transit ridership in U.S. metropolitan areas between 1990 and 2000: A multivariate analysis. Transportation Research Record 1986: 172-181.

Thompson, G., and T. Matoff. 2003. Keeping up with the Joneses: Planning for transit in decentralizing regions. Journal of the American Planning Association 69(3): 296-312.

TRL Limited. 2004. The Demand for Public Transport: A Practical Guide. TRL Report TRL 593.

U.S. Bureau of Economic Analysis (2006a). Employment (by County). Available at http://www.bea.gov/bea/regional/reis/defaultcfm?\&catable=CA25\&series=SIC.

U.S. Bureau of Economic Analysis. 2006b. Population (by county). Available at http://www.bea.gov/bea/regional/reis/default.cfm?catable=CA1-3.

U.S. Bureau of Labor Statistics. 2005a. 2000 Tabulation of unemployment rates from the current population survey. Available at http://www.bls.gov/cps, accessed July 1, 2005.

U.S. Bureau of Labor Statistics. 2005b. Consumer Price Index. Available at http:// www.bls.gov, accessed July 1, 2005.

U.S. Bureau of Labor Statistics. 2005c. Consumer Price Index: Motor fuel. Available at http://www.bls.gov, accessed July 1, 2005.

U.S. Census Bureau. 1982. Census of retail trade. Government Printing Office: Washington, D.C.

U.S. Census Bureau. 2000. Census Transportation Planning Package. Bureau of Transportation Statistics, Washington, DC.

\section{About the Authors}

JefFREY R. BROWn (jrbrown3@fsu.edu) is Associate Professor and Director of the Master's Program in the Department of Urban and Regional Planning at Florida State University. His research interests include the early professionalization of transportation planning, the changing nature of street and highway planning in the United States, transportation finance, and the relevance of different service strategies for making public transit more successful in decentralized urban areas. 
DRISTI NeOG (neog.dristi@sushantschool.org) is an Assistant Professor at the Sushant School of Art and Architecture, Gurgaon, India, and a Fellow of the Sustainable Planet Institute, Gurgaon, India. She is anchoring a Master's program in Sustainable Urbanism at the Sushant School and her research interests include sustainable transportation planning and analysis, transportation and land use dynamics, sustainable development, transit planning and application of geographic information systems (GIS) to sustainable urban planning. 